A Metacognitive Intervention for Teaching Fractions to Students

With or At-Risk for Learning Disabilities in Mathematics

Douglas J. Hacker, Ph.D.

Sharlene A. Kiuhara, Ph.D.

University of Utah

Joel R. Levin, Ph.D.

University of Arizona

Corresponding Authors:

Douglas J. Hacker, Professor

Department of Educational Psychology

University of Utah

1721 Campus Ctr. Dr., Rm. 3220

Salt Lake City, UT 84112-8914

doug.hacker@utah.edu

or

Sharlene A. Kiuhara, Assistant Professor

Department of Special Education

University of Utah

1721 Campus Ctr. Dr., Rm. 2275

Salt Lake City, UT 84112-8914

s.kiuhara@utah.edu 


\begin{abstract}
Assessment data from the United States and international reports of student achievement indicate that upper elementary students are failing to meet basic levels of proficiency in fractions and writing, and that this is particularly prevalent with students with or at-risk for learning disabilities in mathematics. Proficiency with fractions has been identified as foundational for learning higherlevel mathematics but remains one of the most difficult skills for students to learn. In addition, students' difficulty with fractions is exacerbated because of increased chances of comorbidity with language learning problems, particularly difficulties constructing arguments and communicating using writing. We describe $\mathrm{FACT}+\mathrm{R}^{2} \mathrm{C}^{2}$, a language-based, metacognitive instructional intervention that was designed using the Self-Regulated Strategy Development model (SRSD) for teaching foundational concepts of fractions. The results from two studies in which the intervention was administered to upper elementary students who exhibit mathematics difficulties indicated selected increases in students' computational accuracy, quality of mathematical reasoning, number of rhetorical elements, and total words. With evidence of improved performance in these areas, $\mathrm{FACT}+\mathrm{R}^{2} \mathrm{C}^{2}$ holds promise for helping these students become proficient self-regulated learners.
\end{abstract}

Key words: Fractions, Argument writing, Self-regulation, Mathematical reasoning, Selfregulated strategy development 
Running Head: A METACOGNITIVE INTERVENTION FOR TEACHING FRACTIONS 3

\section{A Metacognitive Intervention for Teaching Fractions to Students \\ With or At-Risk for Learning Disabilities in Mathematics}

\section{Introduction}

Essential for teachers who instruct mathematical content is to engage students in mathematical reasoning that makes use of the language of mathematics (Ball and Foranzi 2011). Children make sense and meaning of mathematical content through language, and language ability further supports or reinforces conceptual knowledge needed for learning mathematics (Desoete 2015; Vukovic and Lesaux 2013). Students increase their understanding of the mathematical concepts being taught when they are engaged in activities that involve explaining and elaborating during collaborative problem solving, discussing patterns and inconsistences within proposed solutions, or reconstructing answers after seeking feedback from a teacher or peer (Jonsson et al. 2014), and consequently, they become engaged in developing a "literate identity" (Prain and Hand 2016, p. 430) within the discipline and discourse of mathematics (Schleppegrell 2013).

However, research suggests that students who have difficulties with mathematics often exhibit comorbidity with language difficulties (Krowka and Fuchs 2017). These students are often limited by poor background and vocabulary knowledge for explaining or justifying their solutions. They experience difficulties expressing their ideas in words and evaluating their own words and those of their peers (Lewis and Fisher 2016), and they have difficulty parsing problems into meaningful language chunks and reformulating these chunks into mathematical notation (Montague and Jitendra 2012). In addition, researchers have found that the language difficulties experienced by children with learning difficulties in mathematics are exacerbated by their limited working memory capacity and processing speed, which in turn hamper their abilities 
Running Head: A METACOGNITIVE INTERVENTION FOR TEACHING FRACTIONS 4

to generalize concepts learned to other contexts or mathematics domains (Swanson and Fung 2016).

Although there is debate concerning the terminology used to describe students who have difficulties with mathematics, the term Mathematics Difficulties (MD) has been used to refer to “all children who struggle with math” (Räsänen, 2015, p. 655). Aunio and Tapola (2015) estimate that the prevalence of MD among students is about $20 \%$ with about $4-7 \%$ having serious problems. These estimates appear to be fairly consistent across many countries, including the United States with 25\%, Italy with 35\%, England and Germany with 20\%, and the Netherlands with 10\% (OECD PISA, 2003, cited in Räsänen 2015). We have used the term "Mathematics Learning Difficulties" (MLD) to include children with learning disabilities who are receiving intensive small group instruction in place of regular classroom instruction (Lewis and Fisher 2016) based on a service delivery and funding model used in the United States for children who are classified with a specific learning disability (Individuals With Disabilities Education Act, 2004). We use the term "at risk for MLD" to refer to students who are not classified with a specific learning disability, who score at or below the $35^{\text {th }}$ percentile on standardized tests in mathematics (Fuchs et al. 2013), and who are receiving supplemental instruction along with regular classroom instruction.

Research evidence in special education has identified that an area of mathematics that is difficult for students with MLD is understanding the principles of fractions (Bryant and Bryant, 2008; Geary, 2011; Namkung and Fuchs, 2016), which is considered to be a gateway skill for learning advanced mathematics (Siegler et al. 2012). Mastering fractions is a complex task to teach and learn, especially for students with MLD, because of its multifaceted nature, being comprised of a set of interrelated subconstructs (Charalambous and Pitta-Pantazi 2007), and with 
each one presenting its own unique difficulties for teachers and students. The subconstructs that were the focus of the present research were: understanding unit fractions as numbers and partitioning a whole into equal segments (i.e., the part-whole subconstruct); placing fractions on a number line from 0 to 1 (i.e., the measure subconstruct); and understanding relational concepts of magnitude and equivalence with two or more fractions, $\frac{4}{6}=\frac{2}{3}$ (i.e., the ratio subconstruct).

We focused on these foundational concepts of fractions because they have been shown to contribute to the achievement gap in the United States between elementary grade students with MLD and their typically performing peers (National Center for Education Statistics 2017).

Mazzocco et al. (2013) examined the difficulties that upper elementary students with MLD have with learning foundational concepts of fractions (e.g., understanding the part-whole subconstruct). In that longitudinal study, $5^{\text {th }}$ to $9^{\text {th }}$ grade students were placed into three different groups: typically-achieving students, low-achieving (i.e., students scoring within the $11^{\text {th }}$ to $25^{\text {th }}$ percentile on at least two standardized mathematics assessments), and students with MLD (i.e., students scoring below the $10^{\text {th }}$ percentile on two standardized mathematics assessments). They found that low-achieving students initially had difficulties learning concepts that are introduced in $3^{\text {rd }}$ grade, but by the $5^{\text {th }}$ grade their performance approached the performance of typicallyachieving students. In contrast, students with MLD continued to exhibit difficulties learning these early foundational concepts into the $8^{\text {th }}$ grade. For example, students with more significant learning needs made consistent errors representing $\frac{1}{2}$ and were not developing principles that could transfer to estimating the magnitude of other fractions. 
Running Head: A METACOGNITIVE INTERVENTION FOR TEACHING FRACTIONS 6

Students with and at risk for MLD often have difficulty understanding how fractions can be used to represent an interval or distance from a starting point (i.e., the measure subconstruct) and judging the relative amount and relationship of one fraction to another (i.e., the ratio subconstruct). Fuchs and her colleagues (2013) studied the effects of using the number line as a representation of measure. Those researchers found that applying the number line to compare fractions statistically improved $4^{\text {th }}$ graders fraction knowledge and did not place a burden on their working memory. Additionally, an underlying mechanism that helps students understand the abstract and relative intervals among fractions is visualizing numerical representations, but students with or at risk for MLD often have difficulty using mental representations for understanding the relationship between two fractions (Geary 2011).

Our purpose here is to address the difficulties that students with or at risk for MLD have with both fractions and language by administering a novel language-based, metacognitive intervention that makes use of collaborative writing of arguments and that simultaneously promotes self-regulated learning. Although the writing-to-learn literature has shown that not all conditions of writing lead to learning (Klein 1999), using writing as a tool for learning has been supported in several research arenas. Writing has been shown to: (1) engage various metacognitive behaviors (Pugalee 2002); (2) promote deeper engagement and active reasoning about new ideas (Hacker 2018; Klein 1999); (3) help in the construction and retrieval of mental representations of conceptual and procedural knowledge (Rittle-Johnson et al. 2017); and (4) promote the distribution of learning, permitting multiple opportunities in which to connect mathematical language and to rehearse and fine-tune new information (Bangert-Drowns et al. 2004; Klein 1999). Argumentative writing, in particular, has been shown to help students grapple with complex mathematical concepts together with peers as mathematical skills, knowledge, and 
procedures are cooperatively built through arguments that require students to justify answers with supporting evidence, to identify and discuss patterns, to use representations to understand abstract concepts and symbolic notation, and to define mathematical terms (Klein 1999).

We begin by describing the structure and theoretical grounding of our intervention, called $\mathrm{FACT}+\mathrm{R}^{2} \mathrm{C}^{2}$ (see Section 2.2 for a description of the acronym), followed by a summary of two preliminary research studies that we conducted with upper elementary students with or at risk for MLD. The first was an initial efficacy study in which 10 supplemental instructional groups were assigned randomly to treatment and control condition ( $64 \%$ of students were identified with MLD); and the second was a replication study that used a single-case multiple baseline design (MBD) across five classes (100\% of students were identified with MLD). We address two research questions in each study: (1) How do students with or at risk for MLD who participate in our intervention compare with students in a control condition on distal measures involving foundational knowledge of fractions? and (2) What gains do these students realize on the quality of their mathematical reasoning, as measured by their written paragraphs when prompted to justify their solutions in which they compare two fractions?

\section{Structure and Theoretical Grounding}

Our intervention was designed using the instructional model, Self-Regulated Strategy Development (SRSD; Harris and Graham 2009), which provides explicit instruction across six stages of learning for teaching students metacognitive components for self-regulated learning. Meta-analyses of SRSD involving classroom teachers have shown it to be effective for students with learning disabilities in elementary and secondary school settings, with an effect size of $d=$ 1.33 (Gillespie and Graham 2014). Moreover, the self-regulation components used in SRSD (e.g., goal setting, self-monitoring) have been effective for students in Grades 2 to 6 ( $d=.50$ ) 
Running Head: A METACOGNITIVE INTERVENTION FOR TEACHING FRACTIONS 8

(Graham et al., 2012). We used the SRSD model to serve as a meta-strategy for providing explicit instruction of our intervention that consisted of two learning strategies, FACT (Figure out a plan, Act on it, Compare my mathematical reasoning with a peer, Tie it up in an argument) and $\mathrm{R}^{2} \mathrm{C}^{2}$ (Restate, Reasons, Counterclaim, Conclusion). The strategies were designed to teach the skills and knowledge of foundational concepts of fractions using argumentative writing while promoting self-regulated learning.

Self-regulation has been identified as a key outcome for most pedagogical approaches (Kramarski and Mevarech 2003) and has been recognized as an essential component for learning mathematics (De Corte et al. 2000). According to theories of self-regulated learning, the extent to which SRSD results in students' self-regulation depends on the degree to which it includes instruction of metacognitive procedural knowledge (i.e., cognitive processes that monitor and control one's cognitive and affective states) and metacognitive declarative knowledge (i.e., knowledge or beliefs about one's cognitive and affective states, the states of others, a task, its demands, and how those demands can be met under varying conditions) (Hacker 1998, Pintrich 2002; Schunk and Zimmerman 1997). In addition, these metacognitive components are best learned when they are embedded within the instruction of a specific domain and presented in a systematic fashion by a teacher (Pressley and Harris 2006; Schoenfeld 1992).

Because there are both social and cognitive components of SRSD, we were guided in our design of $\mathrm{FACT}+\mathrm{R}^{2} \mathrm{C}^{2}$ by the social cognitive theory of self-regulated learning proposed by Zimmerman and colleagues (e.g., Schunk and Zimmerman, 1997; Zimmerman 2008). According to this social cognitive theory, self-regulation of learning is acquired through four levels of development that can be recursive in nature: (1) observation, (2) emulation, (3) self-control, and (4) self-regulation. As we describe the six stages of SRSD, we focus on how each stage prepares 
Running Head: A METACOGNITIVE INTERVENTION FOR TEACHING FRACTIONS 9

students for the acquisition of fraction knowledge, and we describe how the acquisition of that knowledge proceeds through the four levels of self-regulated learning.

\subsection{Developing background knowledge}

The first stage of SRSD is Developing Background Knowledge. The teacher starts by providing explanations of the FACT $+\mathrm{R}^{2} \mathrm{C}^{2}$ strategy. Students' observations of their teacher's explanations help to activate and develop their background knowledge necessary for connecting the components of the $\mathrm{FACT}+\mathrm{R}^{2} \mathrm{C}^{2}$ strategy to fractions and how writing can help their understanding of them. The teacher explains to students how solving fraction problems can be accomplished by constructing viable arguments, being precise in their thinking, making sense of problems, and persevering when difficulties arise. In a sense, these explanations serve as a kind of "pep talk" to convince students that the FACT $+\mathrm{R}^{2} \mathrm{C}^{2}$ strategy can benefit them when learning fractions (Zito et al. 2007). Students begin to reflect on what a viable argument is, what it means to be more precise, how to make sense of a problem, and what it takes to persevere in problem solving. That is, through their observations of the teacher, they begin to metacognitively monitor their thoughts about the cognitive processes that are necessary for solving fraction problems.

\subsection{Discuss it}

In the Discuss It stage, students expand on their observations of the teacher's explanations of FACT $+\mathrm{R}^{2} \mathrm{C}^{2}$ by engaging in collaborative teacher-to-student and student-tostudent discussions of them. In these discussions, students talk about mathematical strategies and how they can make problem solving easier, how fraction concepts can be mentally visualized and that they can be visualized in more than one way, and how to make links between the representations and to flexibly switch between them. In other words, they start to think and act like a mathematician (Dreyfus 1991). These discussions help students develop metacognitive 
procedural and declarative knowledge. Not only do they begin to monitor their own thinking, but they begin to control their thinking by revising or changing their thoughts in response to their monitoring but also in response to what they think their peers or teacher are thinking (Kramarski and Mevarech 2003).

To facilitate these discussions, the teacher uses graphic organizers, charts, and sample fraction problems to illustrate the purpose of each step of FACT $+\mathrm{R}^{2} \mathrm{C}^{2}$. Figure out a plan $(\mathrm{F})$ is accomplished by asking questions such as: What is the problem? What mathematical tools can I use? Act on it (A) is encouraged by asking questions such as: What mathematical procedures are needed? What reasons, evidence, and support do I have? Comparing my mathematical reasoning with a peer $(\mathrm{C})$ is facilitated by encouraging self-questions such as: What is similar or different between my answer and other answers? Based on my peers' responses, can I make improvements on my reasons? These questions provide metacognitive guidance to students to clarify or reformulate the problem, generate inferences that fill knowledge gaps, and justify their problem-solving moves (Neuman and Schwarz 1998; Mevarech and Kramarski 1997). As students become familiarized with these questions and the FAC part of FACT $+\mathrm{R}^{2} \mathrm{C}^{2}$ becomes automatized, they begin to develop their own self-guidance to monitor and control their problem solving (Schoenfeld 1992).

The teacher then asks students to reflect on their responses to the foregoing questions and to tie (T) them together by writing arguments to support them. The writing-to-learn literature has provided support for the idea that as students develop competencies in problem solving and critical thinking, writing arguments to support or challenge those competencies can further enhance students' learning of them (De La Paz 2005; Fritjters et al. 2006). By following the genre-specific rules of writing arguments, students are given a rhetorical structure that they can 
Running Head: A METACOGNITIVE INTERVENTION FOR TEACHING FRACTIONS 11

use to evaluate their mathematical thinking and the thinking of their peers. In contrast to other kinds of genre, argument writing helps to deepen students' understanding of the content they are learning and improves the quality of their reasoning (Klein et al. 2017; Nussbaum and Kardash 2005).

Through the act of writing, writers produce external representations of their thoughts that can be accessed and re-accessed by the writer and other readers for further scrutiny. In this way, writing is a metacognitive process through which the writer's thoughts can be observed and potentially restructured and transformed (Hacker, 2018). The external text also makes possible further discussions with peers through which additional conjectures and practice using mathematical language about fractions can occur. Thus, the arguments that students write in response to the questions posed above can be used to develop their conceptual and procedural understanding of fractions, as well as their metacognitive knowledge of monitoring and controlling their mathematical reasoning through clarifying and justifying their problem-solving moves and reformulating their thoughts. Students also develop metacognitive declarative knowledge: They gain knowledge about their own cognitive and affective states while solving fraction problems; they develop understanding of how others think and feel about solving fraction problems; and they develop a deeper understanding of the demands placed on them and how to meet those demands_-all essential elements for self-regulated learning (Zito et al. 2007). Because argument writing about how to solve a mathematics problem is not a common classroom practice, students are provided further assistance by using the $\mathrm{R}^{2} \mathrm{C}^{2}$ portion of the intervention. Students continue to observe the teacher as he or she explains each component of $\mathrm{R}^{2} \mathrm{C}^{2}$. For Restate (R), students are asked questions such as: How did I explain my answer? Did I choose precise math and transition words? Reasons (R) for their answers are prompted by 
Running Head: A METACOGNITIVE INTERVENTION FOR TEACHING FRACTIONS 12

questions such as: Did I provide convincing reasons or evidence? Am I convinced by my

reasons? Students develop Counterclaims (C) or counter answers to their answers by thinking of reasons why their answers may be incorrect. Counterclaims are encouraged by questions such as: Did I develop a good counterclaim? Did I address why the counterclaim is good or not? Finally, students develop a Conclusion (C) to their arguments by asking, Did I wrap up my ideas? Did I choose good math and transition words? Similar to the questions asked of students in the FAC portion of our $\mathrm{FACT}+\mathrm{R}^{2} \mathrm{C}^{2}$ strategy, these questions provide metacognitive guidance to students (Mevarech and Kramarski 1997), but in this case the guidance is focused specifically on the development of strong arguments that support the development of fraction content knowledge and mathematical reasoning.

\subsection{Model it}

In the third stage of SRSD, students continue to observe the teacher and peers as they progress to the emulation level of the development of self-regulation by imitating the teacher's behaviors as he or she models each step of the FACT $+\mathrm{R}^{2} \mathrm{C}^{2}$ strategy to solve problems using multiple representations, such as the concrete-representational-abstract (CRA) sequence. Using multiple representations has received considerable empirical support, particularly in the domain of fractions, and CRA has been shown to be particularly effective with students with or at risk for MLD (Agrawal and Morin 2016; Carbonneau et al. 2013; Rau and Matthews 2017). With repeated observation and emulation of the teacher's behaviors of the FACT $+\mathrm{R}^{2} \mathrm{C}^{2}$ components and CRA instruction, students begin to own the strategy by developing closer and closer approximations of those behaviors (Schunk and Zimmerman, 2007).

Using a think-aloud process, the teacher models the FACT $+\mathrm{R}^{2} \mathrm{C}^{2}$ strategy by choosing a fraction problem to solve and then by modelling each step, while recording notes and ideas to 
help students see each component of the FACT $+\mathrm{R}^{2} \mathrm{C}^{2}$ acronym. In addition to modelling behaviors, through self-talk, self-questioning, and self-explanation, the teacher also models the thoughts, beliefs, and goals associated with the behaviors that are necessary for students to acquire self-efficacy and motivation to engage in self-regulated learning (Zimmerman 2008; Zito et al. 2007).

Modeling the CRA sequence of learning fractions begins with explaining to students that learning progresses through various modes of knowledge representation. Starting with concrete representations, students are shown how to represent their knowledge through motor responses, and learning occurs through kinesthetic and tactile experiences using manipulatives and strategies that require tactile engagement with objects (Wolff et al. 1974). For example, the novice student would compare the magnitude of two fractions by folding a paper strip into equivalent segments. At the representational mode, students learn through the application of visual images, such as diagrams, illustrations, schematics, number lines, or student-drawn visuals (Levin 1983). Finally, with abstract representations, students make use of a symbol system such as the spoken or written word or mathematical notation. A student at this mode of representation would begin to replace using greater than, equal to, or less than with their corresponding abstract symbols, $>,=,<$, respectively. The goal of the student is to communicate his or her understanding of fractions clearly and precisely through language and mathematical notation.

\subsection{Memorize it}

For any strategy to work, students must first have automatic access to it (Harris and Graham, 2009). Teachers encourage automatic retrieval of the FACT $+\mathrm{R}^{2} \mathrm{C}^{2}$ strategy in the Memorize It stage of SRSD by providing students with quizzes, visual aids, or cue cards to commit to memory the steps of FACT and $\mathrm{R}^{2} \mathrm{C}^{2}$ and how each component of the acronyms 
Running Head: A METACOGNITIVE INTERVENTION FOR TEACHING FRACTIONS 14

functions. In addition, the teacher encourages students to describe in their own words how each component works and how each component helps them to understand the procedural and conceptual aspects of fractions.

\subsection{Support it}

Zimmerman and colleagues' third level of development of self-regulation is self-control. Self-control is achieved when students can demonstrate self-regulation while performing tasks that are similar in nature to the task that was modelled. For example, a teacher can model a strategy to convert a mixed number to an improper fraction, and students can now use that strategy independently to convert different mixed numbers to improper fractions. At this point of self-regulation, students are internalizing the modelled strategy but still have not fully formed a complete internal representation of it that can be used beyond the parameters of modelled examples (Schunk and Zimmerman, 2007).

In the Support It stage, the teacher and peers support the development of self-control through explicit and scaffolded modelling of the components of FACT $+\mathrm{R}^{2} \mathrm{C}^{2}$. Students emulate the behaviors demonstrated by the teacher and peers, as they did in earlier stages of SRSD, but after repeated practice, students begin to develop their own goals within the context of the fraction problems. Because generating solutions to fraction problems and writing arguments and counterclaims that refute the solutions can be cognitively challenging for many students with learning disabilities (Harris and Graham 2009), the teacher initially highly scaffolds each step of $\mathrm{R}^{2} \mathrm{C}^{2}$ and involves the students in argument writing collaboratively while going through each problem-solving step of FACT. At the self-control level of development, students have developed metacognitive procedural knowledge of fraction problem solving and begin to set their own goals for monitoring and controlling their learning, and through repeated monitoring 
and control, they develop metacognitive declarative knowledge, which is an awareness of their knowledge of fractions, the strategies for solving fraction problems, and how they can manipulate those strategies to meet the demands of varying problems. With repeated practice, strategies become more automatic, thereby freeing cognitive resources that can be allocated to thinking more deeply about the procedural and conceptual aspects of fractions. Students at this point take ownership of the strategy as they acquire its behavioral, cognitive, physiological, and emotional components (Zito et al. 2007).

\subsection{Independent performance}

In this last stage of SRSD, students fully develop self-regulation when they have internalized the FACT $+\mathrm{R}^{2} \mathrm{C}^{2}$ strategy and can adapt it independently to construct written arguments and counterclaims to support solutions to new fraction problems that differ from previous examples (Schunk and Zimmerman, 2007). Students can now initiate their own goals, adjusting or modifying them based on situational or contextual conditions (Zito et al. 2007). Students write complete paragraphs that explain and justify their solutions to new fraction problems, self-monitor and re-evaluate their progress, and set new goals for applying FACT + $\mathrm{R}^{2} \mathrm{C}^{2}$ without the assistance from peers or teacher. At this higher level of self-regulation, students can maintain their motivation by developing personal goals and develop a sense of self-efficacy for attaining them.

\section{Two preliminary studies supporting FACT $+\mathbf{R}^{2} \mathbf{C}^{2}$}

The development and testing for FACT $+\mathrm{R}^{2} \mathrm{C}^{2}$ were implemented in two preliminary studies (Kiuhara et al. in press, 2019). Detailed accounts of the different methods used in these two studies are reported elsewhere and so only brief summaries of the studies will be reported here. However, it should be noted that neither of the detailed accounts of these two studies 
describes the important role that metacognition plays in the $\mathrm{FACT}+\mathrm{R}^{2} \mathrm{C}^{2}$ intervention, which is explained in detail here. The initial efficacy study was a cluster-based randomized controlled trial in which 10 groups of $4^{\text {th }}$ to $6^{\text {th }}$ grade students with or at risk for MLD $(N=59)$ were randomly assigned to treatment and control conditions. The second study implemented a singlecase multiple-baseline design (MBD) with an associated randomization test (Levin et al. 2018) across five special education teachers who were providing mathematics instruction to $5^{\text {th }}$ and $6^{\text {th }}$ grade students with $\operatorname{MLD}(N=32)$. Adopting a MBD allowed us to identify students who were not responding to the intervention (Odom et al. 2005).

\subsection{Study 1: Cluster-based randomized controlled trial}

\subsubsection{Setting and Participants}

The first study took place in a school district located in the western part of the United States. Ten teachers (six general education teachers and four special education teachers) who were providing supplemental mathematics instruction volunteered to participate. Fifty-nine of their students with or at-risk for MLD also agreed to participate. The students were in Grades 4 $(n=11), 5(n=28)$, and $6(n=20)$. Of the 59 students, $64 \%$ were classified with MLD, $36 \%$ were at-risk learners; $81 \%$ were white; and $56 \%$ were boys. Initial tests of equivalence were conducted using a math computation subtest of the Wide Range Achievement Tests, $4^{\text {th }}$ Ed. (WRAT-4) to measure students' mathematical calculation performance and a written expression subtest from the Wechsler Individual Achievement Test, $3^{\text {rd }}$ Ed. (WIAT-3). No differences were found at the student level between treatment and control conditions for gender, ethnicity (i.e., white or non-white), grade level, or special education status. 


\subsubsection{Design}

Ten teachers and their students were randomly assigned in equal numbers to either the treatment or control conditions using a pre- and posttest group design. Teachers in the treatment condition received two days of professional development before implementing six lessons of the intervention. The training focused on building a community of practice (Ball and Foranzi 2011) and developing teachers' content and pedagogical knowledge by using the same instructional materials and activities teachers would be implementing in the classroom (Harris et al 2015). Four of five teachers in the treatment condition taught the intervention during supplemental instruction time for 45 minutes, three times per week, while one teacher taught for 30 minutes four times per week. Teachers in the control condition provided supplemental instruction using the district's pacing calendar and curriculum, Math Expressions (Fuson 2013) for re-teaching content at the students' grade level. Supplemental instruction occurred for 45 minutes, three times per week.

\subsubsection{Procedure}

The procedure for teaching FACT $+\mathrm{R}^{2} \mathrm{C}^{2}$ followed the SRSD instructional strategy described in section 2 and consisted of six lessons. The fraction content focused on understanding of part-to-whole, measure, and ratio involving comparing fractions by reasoning about their size and representing them on a number line (Charalambous and Pitta-Pantazi, 2007). The writing content focused on writing arguments using reasoning and evidence to support claims and counterclaims, presenting ideas in an organized way, and selecting domain-specific vocabulary to represent the students' mathematical understanding. Teachers in the control condition provided supplemental instruction using the district's mathematics curriculum for re-teaching content in $4^{\text {th }}$ to $6^{\text {th }}$ grades. We administered a survey to teachers in the control condition asking them to 
report the type of instruction and activities they used during the study. They reported that their instruction focused on reviewing adding, subtracting, multiplying and dividing fractions using worksheets. None of the teachers reported teaching or using writing to justify students' solutions.

\subsubsection{Measures}

Students in the treatment and control conditions were administered a distal learning fractions test and a writing test before treatment began. After a teacher in the treatment condition finished teaching the FACT $+\mathrm{R}^{2} \mathrm{C}^{2}$ intervention, her students, as well as students in the control condition, were administered an equivalent fraction test and writing test at posttest.

\subsubsection{Standardized fraction test}

Students' far learning was measured with a standardized fraction test for gains in students' fraction knowledge. The test consisted of 25 multiple-choice items from easyCBM Numbers and Operations (Tindal and Alonzo 2012). The items assessed understanding of fractions (i.e., partitioning, equivalence, comparison fractions for magnitude, ordering fractions from least to greatest).

\subsubsection{Writing test}

The writing test consisted of two equivalent prompts to measure students' accuracy in comparing two fractions from 0 to 1 for equivalence or magnitude and their ability to construct a written paragraph in which they justified their solution. Students were instructed to look at the relationship of two fractions, decide how best to represent the problem (e.g., draw a number line or write down notes), and then write an argumentative paragraph justifying their answer.

Students' papers were typed into a word processing program by two research assistants and checked for reliability. Corrections were made only for spelling because spelling was not being measured. Students' pre-post papers were randomly ordered and scored for mathematical 
reasoning and rhetorical elements by two research assistants. The final score for each participant represented an average of the two scores and consisted of the following variables:

(1) Quality of mathematical reasoning. A rubric was used to score students' papers holistically for logical inclusion of rhetorical elements (e.g., claim or counterclaim) and mathematical accuracy. A general index from 0 to 12 (higher score $=$ higher quality and accuracy) was used. Two research assistants each scored all of the writing measures for reasoning quality, with any disagreements resolved by discussion.

(2) Argumentative elements. Students' papers were scored for the inclusion of six rhetorical elements for writing an argumentative paragraph that was developed for this study: (a) a beginning statement representing the mathematics task; (b) a stated claim or answer to the mathematics problem; (c) reasons and elaborating on the reasons supporting the claim; (d) a counterclaim or an incorrect solution to the problem; (e) reasons and elaborations on the reasons supporting the counterclaim; and (f) a concluding statement. A general index from 0 to 36 was used. Again, two different research assistants independently scored all of the writing measures for a total score representing students' genre knowledge, with any disagreements resolved by discussion.

(3) Total words written. Total words in the students' paragraphs represented a count of the total number of words written using the total word count in the word processing program. A word consisted of a letter or group of letters separated by a space. Agreement between two research assistants was $100 \%$.

\subsubsection{Results}

Treatment fidelity was assessed using checklists of key instructional elements provided for each lesson, and every third lesson was observed and audio was recorded for approximately 
$33 \%$ of all instructional sessions. As an element on the checklist was completed, an observer checked the element as present. A second observer independently listened to the audio recordings and used the same checklists as the first observer. Out of all the instructional steps observed across the five teachers, the mean agreement between the two observers was $96 \%$. All disagreements were resolved by discussion. The six lessons were completed with a mean of 29 class sessions $(S D=6.71$, range $=21-41$ class sessions $)$. Special education teachers taught 10 more class sessions than the general education teachers.

Analyses of variance were performed on the gain scores for the study's four dependent measures. Effect sizes were calculated using Hedges $g$. Results indicated that FACT $+\mathrm{R}^{2} \mathrm{C}^{2}$ accounted for student gains across all measures. For gains in fraction knowledge, student-level analyses indicated that the FACT $+\mathrm{R}^{2} \mathrm{C}^{2}$ students statistically outgained control students by about 2 points $(g=.60)$. Furthermore, comparing the at-risk to the MLD students who received the FACT $+\mathrm{R}^{2} \mathrm{C}^{2}$ instruction, students with MLD demonstrated greater pre-post gains in fraction scores compared to their at-risk peers $(n=12, g=1.04)$. For mathematical reasoning, FACT + $\mathrm{R}^{2} \mathrm{C}^{2}$ students improved their scores by an average of 4.5 points, as compared to a slight decline of .6 points by control students $(g=1.82)$. For number of argumentative elements, the FACT + $\mathrm{R}^{2} \mathrm{C}^{2}$ students' scores increased an average of 6.67 points compared to a slight decrease of .8 points for control students $(g=3.20)$. For total words written, the respective values were an average gain of 47 words compared to an average decrease of 11 words $(g=1.04)$.

Because FACT $+\mathrm{R}^{2} \mathrm{C}^{2}$ students exhibited an increase on all writing measures, the gains they exhibited in their language use attests to the potential value of the instructional intervention for students with MLD. It is important to note the lack of an effect and notable drop in mean scores at posttest for students in the control condition. Prompting students to write an argument 
to justify their answer to a math problem was not a typical learning activity used during supplemental instruction. Previous research suggests that prompting students to construct an argument without explicit instruction on rhetorical text structure limits their capacity for making deeper connections with their learning, lowers their writing quality, and decreases their motivation to write (Graham et al. 2017; Klein et al. 2017).

\subsection{Study 2: Single-case multiple baseline design with an associated randomization test}

\subsubsection{Setting and Participants}

A different school district also located in the western United States provided the setting for our second preliminary study. Five special education teachers, each from a different school, agreed to participate in the study. Each teacher provided specialized instruction in mathematics to students with MLD. The student participants consisted of 31 sixth-graders and 3 fifthgraders. Of the 34 students, 53\% were girls, $85 \%$ were white, and 15\% were Hispanic. Students scored a mean of $56.19(S D=4.73)$ on a mathematics subtest of the WRAT-4 and a mean of $87.21(S D=17.24)$ on a writing subtest of the WIAT-3.

\subsubsection{Design}

Investigating the effects of the intervention components using a single-case multiplebaseline design (MBD) allowed us to make informed decisions for further development of the curriculum (Levin 1992). As a small-sample, multiple-measures, within-subjects variation of a two-condition pre-post "group" design (Hwang and Levin in 2019), each classroom served as its own "control" as 16 weekly probes were administered during baseline and intervention phases (Levin 1992; Odom et al. 2005). We extended the FACT $+\mathrm{R}^{2} \mathrm{C}^{2}$ intervention from Study 1 to include addition and subtraction with like and unlike denominators and multiplication according to the district's pacing calendar for $5^{\text {th }}$ grade. Along with the MBD, 
we selected a randomization statistical test that controlled for Type I error with adequate statistical power (Levin et al. 2018). The restricted Marascuilo-Busk (1988) multiple-baseline design and analysis that was adopted (Levin et al., 2018), in which teachers were randomly assigned to begin the instructional intervention at staggered points in time, minimized threats to internal validity while attempting to provide intervention-effect replication evidence across the five classrooms.

\subsubsection{Procedure}

The procedure for teaching FACT $+\mathrm{R}^{2} \mathrm{C}^{2}$ followed the SRSD instructional strategy described in section 2. To measure direct learning effects during the intervention phase, weekly probes (each representing one of four measures) that were equivalent in content and difficulty were developed and administered during each of the study's 16 weeks to test students' computational accuracy and their writing ability. Distal learning effects were measured using a standardized fractions test that was administered to all students as intervention pre- and posttests (Tindal and Alonzo 2012).

\subsubsection{Measures}

\subsubsection{Computational accuracy of fractions}

Each direct-fraction probe consisted of 14 items that required students to place fractions less than 1 on a number line, compare the magnitude of two fractions, and perform operations including addition, subtraction, and multiplication of fractions. Scoring agreement between two research assistants was $100 \%$.

\subsubsection{Writing test}

The same writing-test format, scoring rubrics, and scoring procedures that were used in Study 1 also were used in Study 2 to provide three measures: (a) quality of mathematical 
reasoning, a general index ranging from 0 to 12 and which consisted of accuracy in comparing two fractions from 0 to 1 and students' ability to construct a written paragraph justifying their solution; (b) argumentative elements, a general index ranging from 0 to 36 and which consisted of six rhetorical elements; and (c) total words written, represented by the total word count in a word processing program. Disagreements between the two scorers were resolved by discussion.

\subsubsection{Results}

In Study 2, treatment fidelity was assessed following the same procedures that were described in Study 1. Checklists of key instructional elements were provided for each lesson, and every third lesson was observed and audio was recorded for approximately $33 \%$ of all instructional sessions. Completed elements on the checklist were noted as present. Again, a second observer independently listened to all of the audio recordings using the same checklists as the first observer. Out of all the instructional steps observed across the five teachers, the mean agreement between the two observers was $87 \%$. All disagreements were resolved by discussion.

Statistically significant classroom-level multiple-baseline effects associated with the implementation of FACT $+\mathrm{R}^{2} \mathrm{C}^{2}$ did not materialize on the study's four focal measures. However, we report here rescaled Non-Overlap of All Pairs (NAP) effect-size indices (Gafurov and Levin 2018), which represent the extent to which the intervention and baseline outcomes do not overlap and which can range from 0 (complete overlap) to 1 (no overlap). The average NAPs for the five teachers' classrooms were: for computational accuracy, .32 (range $=.13$ to .69 ); for mathematical reasoning, .61 (.08 to .97); for number of rhetorical elements, .45 (.15 to .81); and for total words written, .14 (range $=.54$ favoring the baseline phase, to .78$)$. There were, however, student-level statistically significant improvements across the five classrooms on the 
Running Head: A METACOGNITIVE INTERVENTION FOR TEACHING FRACTIONS 24

pre- to posttest mathematics numbers and operations measure $(d=.70)$, indicating that students' mathematics learning exhibited an average increase from the beginning to the end of the study.

Additional analyses were conducted to examine students' performance that corresponded directly with the time points at which each teacher completed specific stages of FACT $+\mathrm{R}^{2} \mathrm{C}^{2}$ instruction. These finer-grained analyses revealed selected statistically significant positive classroom-level effects for both mathematics and writing outcomes associated with the specific stages of instruction. Although students in certain classrooms performed well on all four measures following the introduction of the FACT $+\mathrm{R}^{2} \mathrm{C}^{2}$ intervention, between-classroom variability in scores was evident. A plausible contributor to the paucity of statistical support for intervention effects was the considerable variation in treatment fidelity among the five special education teachers in the study. These findings have informed us of the importance of professional development to increase teachers' self-efficacy and to ensure high fidelity of implementation (Faulkner and Cain 2013).

\section{Discussion}

Our purpose here was to describe a novel language-based, metacognitive intervention for teaching fractions to students with or at risk for MLD and to present empirical evidence indicating that the intervention shows promise for increasing students' knowledge of fractions in three specific areas of fractions (i.e., the part-whole, the measure, and the ratio subconstructs) and for increasing their language abilities as expressed in their argumentative writing. We reported two studies that were guided by two research questions: (1) How do students with or at risk for MLD who participate in our intervention compare with students in a control condition on distal measures involving foundational knowledge of fractions? and (2) What gains do these students 
realize on the quality of their mathematical reasoning as measured by their written paragraphs when prompted to justify their solutions in which they compare two fractions?

Study 1 was a cluster-based randomized controlled trial in which 59 upper elementary students with or at risk for MLD were randomly assigned to treatment and control conditions. The results of this study showed that students who participated in the FACT $+\mathrm{R}^{2} \mathrm{C}^{2}$ intervention showed statistically significant gains over control students in their knowledge of fractions, mathematical reasoning, number of argumentative elements, and total words written, with effect sizes ranging from .60 to 3.20 (Hedges $g$ ).

Study 2 was a single-case multiple-baseline design (MBD) with an associated randomization test (Levin et al. 2018) in which 34 upper elementary, special education students participated in the FACT $+\mathrm{R}^{2} \mathrm{C}^{2}$ intervention taught by five special education teachers. Although not all statistically significant, results showed that the FACT $+\mathrm{R}^{2} \mathrm{C}^{2}$ intervention had positive effects on students' pre- and post-intervention gains in their fraction knowledge and their computational accuracy $(d=.70)$. The intervention also showed selected positive and meaningful effects on students' abilities to express their mathematical reasoning in their argumentative writing, their ability to construct an argument, and the total number of words written.

Our analyses indicated that the results for Study 2 were not as strong as for Study 1; however, additional fine-grained analyses showed classroom-level effects for both mathematics and writing outcomes associated with the specific stages of instruction. In other words, of the five participating special education teachers, some were showing stronger student gains than others. We acknowledge that critical to the success of any classroom intervention is that high fidelity of implementation must be maintained (Desimone 2009; Garet et al. 2001). Success or failure of an intervention must be attributed to the elements of the intervention itself and not to 
idiosyncratic characteristics of those who are implementing it. Admittedly, our FACT $+\mathrm{R}^{2} \mathrm{C}^{2}$ intervention is complex with many interdependent components and requires strong professional development. Although we attempted to provide intensive, sustained, and integrated professional development to our participating teachers, our observations revealed that treatment fidelity for teachers who participated in Study 2 varied. Three of five teachers were observed implementing the intervention with high fidelity compared to the remaining two teachers $(99 \%, 97 \%, 96 \%$ vs. $79 \%$ and $66 \%$, respectively), which indicated that not all teachers had been fully engaged in or implemented the intervention as intended.

Two unique components of our intervention that deserve particular attention when considering the design of supplemental or specialized mathematics instruction for students with or at-risk for MLD are the role of self-regulation and using writing as a learning activity. Other researchers have incorporated metacognition into their instruction of mathematics (e.g., Kramarski and Mevarech 2003; Pugalee 2002; Schoenfeld 1992). However, in our implementation of SRSD, we specifically aligned its six stages (i.e., develop background knowledge, discuss it, model it, memorize it, support it, and independent practice) to Zimmerman's four-level model of self-regulation (i.e., observation: emulation, self-control, and self-regulation). In addition, SRSD has been used in other research to instruct mathematics (see Case et al. 1992; Cassell and Reid 1996; and Cuenca-Carlino 2016). However, none of this research incorporated writing as a learning activity. A finding common across these studies and the research we present here is that the metacognitive components embedded in SRSD (e.g., explicit instruction, modelling, think aloud, self-reinforcement) do contribute to the development of metacognitive procedural and declarative knowledge for generating conceptual and procedural knowledge of mathematics. 
Moreover, writing serves as a metacognitive tool to help students monitor and control their thinking (Hacker, 2018). For students with and at-risk for MLD, the focus on language development and the explicit instruction for using writing as a tool for learning mathematics helps students develop their mathematical thinking and ability to construct arguments to justify their claims and counterclaims with supporting evidence. By examining their own writing, students can re-read and scrutinize their thoughts, identify patterns in their thinking, share and collaborate with peers regarding their thoughts about fractions, and think and articulate more abstractly about the mathematical concepts they are learning.

Teachers of mathematics, and fractions in particular, may be able to increase the effectiveness of their instruction by using the $\mathrm{FACT}+\mathrm{R}^{2} \mathrm{C}^{2}$ strategy, which integrates the theoretical perspectives of self-regulated learning proposed by Zimmerman and colleagues with the practices prompted by SRSD. Through observation, students monitor the teacher's explanations of strategy use, the use of multiple representations, what they know or do not know about fractions and writing, what they should be monitoring in the upcoming instruction, and their peers' responses. Students' observations are further elaborated through collaborative discussions with the teacher and peers, during which they learn not only how to monitor their thoughts but also how to control them by revising or updating them in light of new information discussed. Using modelling and "think alouds", the teacher shows students how to emulate fraction problem solving using multiple representations. Students' metacognitive monitoring and control are further developed by imitating the teacher's behaviors and by writing arguments to justify their answers with supporting evidence. As students accumulate greater experiences and knowledge of the $\mathrm{FACT}+\mathrm{R}^{2} \mathrm{C}^{2}$ strategy, practice more problems, and gain more experience with writing, they further develop their metacognitive declarative knowledge of fractions and writing. Memorizing 
Running Head: A METACOGNITIVE INTERVENTION FOR TEACHING FRACTIONS 28

the strategy and receiving further teacher and peer support help to strengthen students' skills and metacognitive procedural and declarative knowledge to the point of developing self-control of their problem solving and ultimately self-regulation as evidenced by independent performance on fraction problems and writing arguments to support their performance.

The research we present here shows promise for the classroom practice of FACT $+\mathrm{R}^{2} \mathrm{C}^{2}$ and encouragement to conduct further studies with fractions. One line of research would be to isolate and manipulate the metacognitive components embedded in SRSD to ascertain which elements of the strategy, singly or in concert, are contributing to students' learning. Further research is needed to examine how students are self-regulating their fraction problem solving. Such examinations would provide insights into how active self-regulation enhances the teaching and learning of fractions and potentially enhances our understanding of self-regulation theory itself. These insights into self-regulation could be gained through a detailed analysis of students' written products. Finally, our next steps are to improve the processes by which professional development of mathematical content and pedagogy can be improved upon to address treatment fidelity. Addressing teacher "buy in" (with respect to the delivery of a novel instructional intervention), treatment fidelity, and the skills and knowledge needed to teach content-rich mathematics will be important for evaluating the mathematics outcomes of students with or atrisk for MLD. 
Running Head: A METACOGNITIVE INTERVENTION FOR TEACHING FRACTIONS 29

\section{References}

Agrawal, J., \& Morin, L. L. (2016). Evidence-based practices: Applications of concrete representational abstract framework across math concepts for students with mathematics disabilities. Learning Disabilities Research \& Practice, 31, 34-44.

Aunio, P., \& Tapola, A. (2015). Children with low performance in mathematics and interventions. In P. Aunio, R. Mononen, \& A. Laine, Mathematical learning difficulties—snapshots of current European research. LUMAT, 5, 664-667.

Ball, D. L., \& Forzani, F. M. (2011). Building a common core for learning to teach: And connecting professional learning to practice. American Educator, 35, 17.

Bangert-Drowns, R. L., Hurley, M. M., \& Wilkinson, B. (2004). The effects of school-based writing-to-learn interventions on academic achievement: A meta-analysis. Review of Educational Research, 74, 29-58.

Bryant, B. R., \& Bryant, D. P. (2008). Mathematics and learning disabilities. Learning Disability Quarterly, 31, 3-11.

Case, L. P., Harris, K. R., \& Graham, S. (1992). Improving the mathematical problem-solving skills of students with learning disabilities: Self-regulated strategy development. The Journal of Special Education, 26, 1-19.

Cassel, J., \& Reid, R. (1996). Use of a self-regulated strategy intervention to improve word problem-solving skills of students with mild disabilities. Journal of Behavioral Education, 6, 153-172.

Carbonneau, K. J., Marley, S. C., \& Selig, J. P. (2013). A meta-analysis of the efficacy of teaching mathematics with concrete manipulatives. Journal of Educational Psychology, $105,380-400$. 
Running Head: A METACOGNITIVE INTERVENTION FOR TEACHING FRACTIONS 30

Charalambous, C. Y., \& Pitta-Pantazi, D. (2006). Drawing on a theoretical model to study students' understanding of fractions. Educational Studies in Mathematics, 64, 293-316.

Cuenca-Carlino, Y., Freeman-Green, S., Stephensen, G. W., \& Hauth, C. (2916). Self-regulated strategy development for teaching multi-step equations to middle school students struggling in math. The Journal of Special Education, 50, 75-85.

De Corte, E., Versaffel, L., \& Eynde, P. O. (2000). Self-regulation: A characteristic and a goal of mathematics education. In M. Boekaerts, P. R., Pintrich, \& M. Ziedner (Eds.), Handbook of self-regulation (pp. 687-726). San Diego, CA: Academic Press.

De La Paz, S. (2005). Effects of historical reasoning instruction and writing strategy mastery in culturally and academically diverse middle school classrooms. Journal of Educational Psychology, 97, 139-156.

Desimone, L. M. (2009). Improving impact studies of teachers' professional development: Toward better conceptualizations and measure. Educational Researcher, 38, 181-199. Desoete, A. (2015). Language and math. In P. Aunio, R. Mononen, \& A. Laine, Mathematical learning difficulties — snapshots of current European research. LUMAT, 5, 647-674.

Dreyfus, T. (1991). Advanced mathematical thinking processes. In D. Tall (Ed.), Advanced mathematical thinking (pp. 25-41). Dordrecht, The Netherlands: Kluwer Academic Press.

Faulkner, V. N., \& Cain, C. R. (2013). Improving the mathematical content knowledge of general and special educators: Evaluating a professional development module that focuses on number sense. Teacher Education and Special Education 36, 115-131.

Fritjters, S., Van Dam, G.I, \& Rijlaarsdam, G. (2006). Effects of dialogic learning on valueloaded critical thinking. Learning and Instruction, 18, 66-82. 
Running Head: A METACOGNITIVE INTERVENTION FOR TEACHING FRACTIONS 31

Fuchs, L. S., Schumacher, R. F., Long, J., Namkung, J., Hamlett, C., Cirino, P. T. Jordan, N. C., Siegler, R., Gersten, R., \& Changas, P. (2013). Improving at-risk learners’ understanding of fractions. Journal of Educational Psychology, 105, 683-700.

Fuson, K. C. (2013). Math Expressions. Boston, MA: Houghton Mifflin Harcourt.

Gafurov, B. S., \& Levin, J. R. (2018). ExPRT (Excel Package of Randomization Tests):

Statistical Analyses of Single-Case Intervention Data; current Version 3.1 (June 2018) is retrievable from the ExPRT website at http:/ex-prt.weebly.com.

Garet, M. S., Porter, A. C., Desimone, L., Birman, B. G., \& Yoon, K. W. (2001). What makes professional development effective? Results for a national sample of teachers. American Educational Research Journal, 38, 915-945.

Geary, D. C. (2011). Consequences, characteristics, and causes of mathematical learning disabilities and persistent low achievement in mathematics. Journal of Developmental \& Behavioral Pediatrics, 32, 250-263.

Gillespie, A., \& Graham, S. (2014). A meta-analysis of writing interventions for students with learning disabilities. Exceptional Children, 80, 454-473.

Graham. S., McKeown, D., Kiuhara, S. A., Harris, K. R. (2012). A meta-analysis of writing instruction for students in the elementary grades. Journal of Educational Psychology, 204, 879-896.

Hacker, D. J. (1998). Metacognition: Definitions and empirical foundations. In D. J. Hacker, J. Dunlosky, \& A. C. Graesser (Eds.), Metacognition in educational theory and practice, (pp. 1-23). Mahwah, NJ: Erlbaum.

Hacker, D. J. (2018). A metacognitive model of writing: An update from a developmental perspective. Educational Psychologist, 53, 220-237. 
Hansen, N., Jordan, N. C., \& Rodrigues, J. (2017). Identifying learning difficulties with fractions: A longitudinal study of student growth from third through sixth grade. Contemporary Educational Psychology, 50, 45-59.

Harris, K. R., \& Graham, S. (2009). Self-regulated strategy development in writing: Premises, evolution, and the future. Teaching and Learning Writing, 6, 113-135.

Harris, K. R., Graham, S., \& Adkins, M. (2015). Practice-based professional development and self-regulated strategy development for Tier 2, at-risk writers in second grade. Contemporary Educational Psychology, 40, 5-16.

Hwang, Y., \& Levin, J. R. (2019). Application of a single-case intervention procedure to assess the replicability of a two-component instructional strategy. Contemporary Educational Psychology, 56, 161-170.

Individuals With Disabilities Education Act, 20 U.S.C. $§ 1400$ (2004).

Jonsson, B., Norqvist, M., Liljekvist, Y., \& Lithner, J. (2014). Learning mathematics through algorithmic and creative reasoning. The Journal of Mathematical Behavior, 36, 20-32.

Kiuhara, S. A., Gillespie Rouse, A., Dai, T., Witzel, B., Morphy, P., \& Unker, B. (in press). Selfregulated strategy development: An instructional model for constructing arguments to develop fraction knowledge. Journal of Educational Psychology.

Kiuhara, S. A., Levin, J. R., Tolbert, M., \& MacKay, M. (2019). FACT and self-regulated strategy development: Illustration of a multiple baseline design with an associated randomization test. Manuscript in preparation.

Klein, P. D. (1999). Reopening inquiry into cognitive processes in writing-to-learn. Educational Psychology Review, 11, 203-270. 
Running Head: A METACOGNITIVE INTERVENTION FOR TEACHING FRACTIONS 33

Klein, P.D., Haug, K. N., \& Arcon, N. (2017). The effects of rhetorical and content subgoals on writing and learning. The Journal of Experimental Education, 85, 291-308.

Kramarski, B., \& Mevarech, Z. R. (2003). Enhancing mathematical reasoning in the classroom: The effects of cooperative learning and metacognitive training. American Educational Research Journal, 40, 281-310).

Krowka, S. K., \& Fuchs, L. S. (2017). Cognitive profiles associated with responsiveness to fraction intervention. Learning Disabilities Research \& Practice, 32, 216-230.

Levin, J. R. (1983). Pictorial strategies for school learning: Practical illustrations. In M. Pressley \& J. R. Levin (Eds.), Cognitive strategy research: Educational applications (pp. 213237). New York: Springer-Verlag.

Levin, J. R. (1992). Single-case research design and analysis: Comments and concerns. In T. R. Kratochwill \& J. R. Levin (Eds.), Single-case research design and analysis: New directions for psychology and education (pp. 213-224). Hillsdale, NJ: Erlbaum.

Levin, J. R., Ferron, J. M., \& Gafurov, B. S. (2018). Comparison of randomization-test procedures for single-case multiple-baseline designs. Developmental Neurorehabilitation, $21,290-311$.

Lewis, K. E., \& Fisher, M. B. (2016). Taking stock of 40 years of research on mathematical learning disability: Methodological issues and future directions. Journal for Research in Mathematics Education, 47, 338-371

Marascuilo, L. A., \& Busk, P. L. (1988). Combining statistics for multiple-baseline AB and replicated ABAB designs across subjects. Behavioral Assessment, 10, 1-28. 
Running Head: A METACOGNITIVE INTERVENTION FOR TEACHING FRACTIONS 34

Mazzocco, M. M. M., Myers, G. F., Lewis, K. E., Hanich, L. B., \& Murphy, M. M. (2013). Limited knowledge of fraction representations differentiates middle school student with mathematics learning disability (dyscalculia) versus low math achievement. Journal of Experimental Child Psychology, 115, 371-387.

Mevarech, Z. R., \& Kramarski, B. (1997). IMPROVE: A multidimensional method for teaching mathematics in heterogeneous classrooms. American Educational Research Journal, 3, 365-395.

Montague., M. \& Jitendra, A. K. (2012). Research-based mathematics instruction for students with learning disabilities. In H. Forgasz \& F. Rivera (Eds.), Towards equity in mathematics Education: Advances in Mathematics Education (pp. 481-502). Berlin: Springer.

National Center for Education Statistics. Institute of Education Sciences National Assessment of Educational Progress for Mathematics. (2017). The Nation's Report Card: Mathematics 2017. Institute of Education Sciences, U. S. Department of Education, Washington, D.C.

Neuman, Y., \& Schwarz, B. B. (1998). Is self-explanation while solving problems helpful? The case of analogical problem solving. British Journal of Educational Psychology, 68, 1524.

Nussbaum, E. M., \& Kardash, C. M. (2005). The effects of goal instructions and text on the generation of counterarguments during writing. Journal of Educational Psychology, 97, 157-169. 
Running Head: A METACOGNITIVE INTERVENTION FOR TEACHING FRACTIONS 35

Odom, S. L., Brantlinger, E., Gersten, R., Horner, R. H., Thompson, B., \& Harris, K. R. (2005). Research in special education: Scientific methods and evidence-based practices. Council for Exceptional Children, 71, 137-148.

Organization for Economic Cooperation and Development. (2003). Literacy skills for the world of tomorrow. Further results from PISA 2000. Paris.

Pintrich, P. R. (2002). The role of metacognitive knowledge in learning, teaching, and assessing. Theory Into Practice, 41, 219-225.

Prain V., \& Hand, B. (2016). Coming to know more through and from writing. Educational Researcher, 45, 430-434.

Pressley, M., \& Harris, K. R. (2006). Cognitive Strategies Instruction: From Basic Research to Classroom Instruction. In P. A. Alexander \& P. H. Winne (Eds.), Handbook of educational psychology (pp. 265-286). Mahwah, NJ, US: Lawrence Erlbaum Associates Publishers.

Pugalee, D. K. (2002). Writing, mathematics, and metacognition: Looking for connections through students' work in mathematical problem solving. School Science and Mathematics, 101, 236-245.

Räsänen, P. (2015). Longitudinal studies on dyscalculia. In P. Aunio, R. Mononen, \& A. Laine, Mathematical learning difficulties—snapshots of current European research. LUMAT, 5, 651-655.

Rau, M. A., \& Matthews, P. G. (2017). How to make 'more' better? Principles for effective use of multiple representations to enhance students' learning about fractions. ZDM Mathematics Education. Advance online publication. 
Rittle-Johnson, B., Loehr, A. M., \& Durkin, K. Promoting self-explanation to improve mathematics learning: A meta-analysis and instructional design principles. $Z D M$ Mathematics Education, 49, 599-611.

Schleppegrell, M. J. (2013). The role of metalanguage in supporting academic language development. Language Learning, 63, 153-170.

Schoenfeld, A. H. (1992). Learning to think mathematically: Problem solving, metacognition, and sense-making in mathematics. In D. Grouws (Ed.), Handbook for research on mathematics teaching and learning (pp. 334-370). New York: MacMillan.

Schunk, D. H., \& Zimmerman, B. J. (1997). Social origins of self-regulatory competence. Educational Psychologist, 32, 195-208.

Siegler, R. S., Duncan, G. J., Davis-Kean, P. E., Duckworth, K., Classens, A., Engel, M., Susperreguy, M. I., \& Chen, M. (2012). Early predictors of high school mathematics achievement. Psychological Science, 23, 691-697.

Swanson, H. L. \& Fung, W. (2016). Working memory components and problem-solving accuracy: Are there multiple pathways? Journal of Educational Psychology, 108, 11531177.

Tindal, G., \& Alonzo, J. (2012). easyCBM. Boston, MA: Houghton Mifflin Harcourt.

Vukovic, R. K., \& Lesaux, N. K. (2013). The language of mathematics: Investigating the ways language counts for children's mathematical development. Journal of Experimental Child Psychology, 115, 227-244.

Wolff, P., Levin, J. R., \& Longobardi, E. T. (1974). Activity and children's learning. Child Development, 45, 221-223. 
Zimmerman, B. J. (2008). Investigating self-regulation and motivation: Historical background, methodological developments, and future prospects. American Educational Research Journal, 45, 166-183.

Zito, J. R., Adkins, M., Gavins, M., Harris, K. R., \& Graham, S. (2007). Self-regulated strategy development: Relationship to the social-cognitive perspective and the development of self-regulation. Reading \& Writing Quarterly, 23, 77-95. 